\title{
TRABALHO E EDUCAÇÃO EM TEMPOS DE PANDEMIA: ENTREVISTA COM GEORGINA HELENA LIMA NUNES'
}

\author{
Por Ana Paula F. D’Avila e Eduardo V. Bonaldi²
}

\section{Resumo}

A pandemia causada pelo SARS-CoV-2 suscitou no Brasil o tema da desigualdade como tema transversal, em nosso país a crise sanitária somou-se a crise econômica e política. Entretanto, consideramos que a pandemia nos alerta para a especificidade histórica brasileira a qual consiste no racismo estrutural e institucional presente em nossa sociedade. Nesse sentido, esta entrevista visa refletir sobre alguns dos efeitos da pandemia sobre o trabalho e educação para a população negra, bem como compreender suas formas de (re) existir.

Ana Paula e Eduardo: Cara professora Georgina, agradecemos o aceite em participar da entrevista. O objetivo deste dossiê consiste em refletir sobre o trabalho e a educação no contexto da pandemia causada pelo SARS-CoV-2, popularmente conhecido como Covid-19. Nesse sentido, a primeira questão que colocamos, se refere aos efeitos da pandemia na vida e no trabalho de mulheres negras.

Georgina: A esfera do privado sofre alterações imensas e repercute, talvez, em desigual proporção na realização do trabalho, visto que este se torna prioritário frente a outras questões tão essenciais à vida, como o direito ao descanso. Trata-se, então, de mais uma forma de expropriação das nossas potencialidades humanas, uma vez que, em sociedades capitalistas, a concepção de trabalho se conjuga com processos de desumanização/exploração radical. No que se refere às mulheres negras, uma minoria tem a possibilidade do teletrabalho, por ser histórica a sua

\footnotetext{
1 Ver currículo da entrevistada no final do texto. Essa entrevista on-line foi realizada no dia 11 de novembro de 2020 através da plataforma WEBConf da Universidade Federal de Pelotas (UFPel).

2 Ana Paula Ferreira D'Avila é pós-doutoranda em Sociologia pela Universidade Federal de Pelotas (UFPel). Doutora em Sociologia pela Universidade Federal do Paraná (UFPR), com estágio doutoral no Centro de Estudos Sociais da Universidade de Coimbra (UC), Portugal. E-mail: anapaulasocio10@gmail.com Cidade: Pelotas.

Eduardo Vilar Bonaldi é Professor Adjunto do Departamento de Sociologia e Ciência Política da Universidade Federal de Santa Catarina (UFSC). Professor do Programa de Pós-Graduação em Sociologia e Política (UFSC). E-mail: eduvilarbon@gmail.com Cidade: Florianópolis.
} 
ocupação em trabalhos não formais, de baixa remuneração. Estas são maioria no processo de proletarização da força de trabalho feminina e conjugam, às suas responsabilidades de sobrevivência individual, um grande número de pessoas, na medida em que muitos lares são chefiados por elas. A pandemia expõe, a olho nu, as clivagens sociais, raciais e de gênero, e, conforme foi amplamente divulgado, a primeira mulher a morrer de covid-19 no Brasil foi uma mulher negra e empregada doméstica; junto à letalidade nada democrática do vírus, mães perdem filhos, cotidianamente, pelo drama das mazelas do racismo, que, sob o ponto de vista institucional e individual, define a quem a morte assume, de forma inexplicável, a condição de direito. O teletrabalho é hegemonicamente branco e tal constatação evidenciou os níveis de desemprego nos momentos mais severos do distanciamento social; em oposição ao teletrabalho estão as atividades de menor status social, principalmente daquelas que sempre estiveram nas ruas trabalhando e que vai ao encontro da afirmação da escritora François Vergés (2020), de que as mulheres, principalmente as negras, são invisiveis, elas "abrem a cidade" (trabalham, muitas vezes, na madrugada) e "limpam o mundo".

Ana Paula e Eduardo: Pesquisas ${ }^{3}$ têm evidenciado que a população negra está mais exposta ao contágio pelo vírus da Covid-19. Também sabemos que a letalidade do vírus é maior entre a população negra. Quais seriam as razões que determinam essa maior vulnerabilidade à Covid-19 entre a população negra?

Georgina: Sim, isso é incontestável. Anterior à pandemia havia um declínio das políticas públicas com enfoque em raça/cor. Principalmente no que diz respeito às políticas específicas relativas à saúde integral da população negra; neste momento, às condições inadequadas de moradia, mobilidade, saneamento básico, soma-se a sobrecarga do Sistema Único de Saúde, que em tempos anteriores à pandemia assumia para si a existência de um

\footnotetext{
3 AQUINO, Celso. Quase 65\% dos casos de coronavirus no Ceará acometem a população negra. Número é muito maior que a média nacional de 38,41\%. Brasil de Fato | Fortaleza (CE). 15 de Outubro de 2020. Disponivel em: https://www.brasildefato.com.br/2020/10/15/quase-65-dos-casosde-coronavirus-no-ceara-acometem-a-populacao-negra
} 
racismo institucional nos seus serviços. Violências obstétricas, esterilizações não consentidas, menosprezo em exames corporais, são amostras da violência estatal sobre os corpos negros, cuja repulsa a um tratamento digno é materializada em outras atitudes, tais como o joelho asfixiante da "segurança" pública em nossas gargantas e outras inúmeras violências, tanto físicas como simbólicas, presentes, por exemplo, nos contextos educacionais em todos os niveis. A universidade é um exemplo; uma agência, muitas vezes, epistemicida.

Ana Paula e Eduardo: Como o teletrabalho tem impactado as dinâmicas de sociabilidade, hierarquia e de disciplinamento na esfera do trabalho?

Georgina: Creio que parte do tema contemplei na questão 1. Em relação ao disciplinamento, diria que a vida frente à tela tende a ser duradoura, mesmo em tempos pós-pandêmicos. É da ordem global, da "colonialidade do poder", conforme formulação de Anibal Quijano, a imposição de uma regulação dos tempos e espaços que, comprimidos por uma virtualidade, produzem corpos assujeitados, ainda que todas as sujeições sempre sejam relativas; aposto na construção de algumas "burlas" a esse sistema. É da "natureza" das gentes, que fazem parte desse hierárquico mundo do trabalho, reações inusitadas a múltiplas formas de opressão e aniquilamento. Neste momento que escrevo, vislumbro pela janela, há um vasto campo (algo inédito no contexto urbano) e também algumas flores (bem-me-quer), aciono dispositivos da memória e, por meio deles, relembro uma infância de trabalho junto à mãe, que era empregada doméstica, e igualmente o envolvimento orgânico na luta antirracista desde sempre. Neste teletrabalho, invariavelmente emerge o tempo-espaço para a resistência, contra-hegemonia que também pode ser mobilizada por este espaço virtual, na instantaneidade de um olhar para a janela.

Ana Paula e Eduardo: Quais os conflitos e demandas trabalhistas que começam a surgir nesse contexto? 
Georgina: Não sei se seriam exatamente demandas trabalhistas, mas, por exemplo, a compreensão de que postos de trabalhos não acolhem, as "classes que vivem do trabalho" conforme argumenta Ricardo Antunes e que estas classes não são homogêneas, e que a sua diversidade tende a hierarquizá-las em termos de remuneração e prestígio social. Temos então um esfacelamento, assim se espera, do discurso "empreendedor", que, de alguma forma, requenta algumas sentenças antigas de que crises se enfrentam com criatividade, por exemplo. A necessidade do auxílioemergencial para alguns/mas, não obstante algumas irregularidades, sinaliza o nível de desigualdade social a que estamos sujeitos/as. Sob o ponto de vista metafórico, algumas populações vivem sucessivas "quarentenas". Posto isso, é urgente se pensar em renda minima e em Estado forte para as políticas sociais, e não o inverso, ou seja, um estado neoliberal, mercadológico e genocida. A categoria trabalho, e consequentemente trabalhador/a, é polissêmica; se formos pensar nos povos tradicionais e mais especificamente nas populações quilombolas, a relação com o trabalho está intimamente ligada ao território, e este não é apenas um território geográfico/físico. Trata-se de um mundo, também, espiritual, cultural e ancestral; na pandemia, comunidades quilombolas do Maranhão sofreram ordem de "despejo" do governo federal quando o protocolo da ciência era "fique em casa". Os territórios quilombolas estão, desde 1988, em conformidade com o artigo 68 da Constituição Federal, na luta por regularização fundiária, que deve ser acompanhada por políticas que favoreçam o etnodesenvolvimento. E, leia-se, nesses territórios, a presença das mulheres é forte na posição de mantenedoras da vida material, espiritual e política. Nesse sentido, para não fugir à questão das demandas trabalhistas, diria que elas assumem um vasto espectro, inclusive pautadas na diversidade de gênero e raça como agravantes de condições de vida, em contextos urbanos rurais.

Ana Paula e Eduardo: Há diferenças geracionais no que se refere à preferência ou capacidade de adaptação ao teletrabalho? 
Georgina: Sim, a relação com a tecnologia é diferenciada no que diz respeito às especificidades geracionais. Todavia, pensaria não apenas na questão da diferença etária, porque o uso das mídias digitais é diverso em termos de formas e fins de utilização. Por isso, a relação com a máquina pode ser diferente e demarcada por outros elementos, também, com características de outra ordem. A palavra "geracional" também pode ser associada à expressão "herança-geracional", estudada pelo sociólogo Carlos Hasenbalg, que demonstrou estatisticamente as sucessivas desvantagens que eram transferidas entre uma geração e outra de famílias negras. Nesse sentido, o home office não é realidade para lares de famílias negras; existe uma inacessibilidade a equipamentos, à rede de internet, enfim, a todas as exceções que a divisão racial do trabalho produz. O home office requer um olhar estendido a uma conjugação de fatores estruturais que refletem, igualmente, a forma como a sociedade se apresenta em todas as suas cisões e binarismos: homens-mulheres, brancos e não brancos; urbanos-rurais; heterossexuais em contraponto a uma diversidade sexual; jovens e velhos; adultos e crianças...

Ana Paula e Eduardo: Recentemente, saiu uma pesquisa do Instituto Pólis ${ }^{4}$ sobre a maior mortalidade por Covid-19 na população negra em São Paulo. Dentre os principais motivos estão as piores condições de renda, grau de instrução, tipo de trabalho e vínculo empregatício - razões que são resultantes do racismo estrutural. No caso da educação, de acordo com a sua experiência, quais são os primeiros impactos para a população negra?

Georgina: A educação formal para a população negra, em períodos pré e pós-abolição da escravidão sempre foi perpassada por fatores ora legais e ora ideológicos de interdição. Negros e negras criaram estratégias de escolarização nas irmandades, clubes associativos, nas organizações politicas e culturais (Frente Negra Brasileira e Teatro Experimental do Negro)

\footnotetext{
4 BOEHM, Camila. Mortalidade por covid-19 é maior entre população negra em São Paulo. Estudo é da organização não governamental Instituto Pólis. Agência Brasil. 28/08/2020. São Paulo. Disponível em: Fonte: https://agenciabrasil.ebc.com.br/saude/noticia/2020-08/mortalidade-por-covid-19-emaior-entre-populacao-negra-em-sao-paulo Acesso em: 30 de ago 2020.
} 
até chegar à efetivação de algumas estruturas legais que diminuíssem o fosso educacional em relação ao segmento branco, tais como a lei 10639/03, as Diretrizes Curriculares Nacionais para Educação Escolar Quilombola e a Lei das Cotas (12.711/12), esta que, apesar de se constituir numa subcota para pretos e pardos (negros) e indígenas, ainda assim, é fruto histórico e inquestionável do Movimento Social Negro. No entanto, as conquistas legais nem sempre se efetivam no interior das escolas e universidades, e a prova disso é a forma como currículos (artefatos culturais de saber e poder) são resistentes a mudanças. Ressalto que um currículo não é apenas um rol de conteúdos; é uma relação social que se estabelece com um conjunto de pressupostos que (des)educam as instituições, na perspectiva de que, por intermédio da educação, a injustiça social que advém, no dizer de Boaventura de Sousa Santos, como decorrente de outras injustiças, tais quais a jurídica e, principalmente, a epistêmica, sejam superadas. É evidente que, em tempos de pandemia, todos/as serão prejudicados/as, mas neste "todos/as", a exemplo da etimologia da palavra pandemia - para todos -, a distribuição do ônus, como sempre, será desigual. Os impactos serão a manutenção da histórica assimetria entre a formação escolar e acadêmica entre diferentes grupos étnico-raciais, no entanto, quero salientar que negros/as se educam permanentemente diante das investidas invisiveis, seja do vírus, seja do preconceito. A diferença entre escolarização e educação incide em um conjunto de experiências que negros/as têm, cotidianamente, construído, e que desafiam a racionalidade branca, que, de forma bastante extrativista, ainda insiste em objetificar como "negro-tema" aquilo que, segundo Guerreiro Ramos, trata-se de "negro-vida". Nesta pandemia, perdem-se tempos de certificação escolar e acadêmica, isso está posto, mais uma vez, pelo racismo estrutural. Mas, na contramão, esquemas cognitivos, intelectuais e teóricos, não cindidos da prática (práxis, portanto!), levam-nos a crer que ainda continuamos a ser e viver nós por nós "mesmos/as". A uma crescente mercantilização da educação e da vida, reafirmar que "vidas negras importam", não é a repetição global de um lema que, se não estivesse permeado por estratégias educativas de resistência, teria baixa intensidade de contestação e mudança. "Vidas negras importam" é sinônimo de "parem de nos matar", e, de alguma forma, à educação formal também se destina o 
recado: é urgente uma educação que paute o racismo epistêmico e o privilégio branco expresso em uma matriz de conhecimento ocidental que perpetua assimetrias em todos os campos da existência humana.

Ana Paula e Eduardo: Quais seriam os impactos do ensino remoto sobre os estudantes negros, sobre os cotistas?5

Georgina: Sem dúvida alguma, se pensarmos na politica de ensino superior tem a questão da política de cotas, que na verdade se constitui uma subcota para a população negra, porque o critério maior é ser estudante de escola pública, aí já começa um grande problema. A questão social é diferente da questão racial e o fato de ser estudante da escola pública, necessariamente, não é sinônimo de vulnerabilidade e tem mais uma outra questão: as ações afirmativas para negros deveriam estar condicionadas a questão social?. A escola pública, como disse, não é sinônimo de vulnerabilidade social e a questão racial tem uma vinculação com a questão econômica porque os negros estão nas piores condições de trabalho, estão no subemprego, ou seja, juntamente com a divisão social do trabalho há a divisão racial do trabalho. Em todos os momentos anteriores a pandemia a população negra acumula uma série de desvantagens, mas apenas com as politicas afirmativas houve um maior acesso ao ensino superior.

Entretanto, as políticas afirmativas, nos moldes que estão colocadas, principalmente da Lei 12.711/12 tem favorecido principalmente a população não negra, a universidade ela nunca foi tão branca quanto tem sido agora. Há sim uma maior quantidade de negros que se tinha outrora, por exemplo, em 2001 nós tínhamos $2 \%$ de negros no ensino superior, hoje nós temos uma base de 18\% de negros. Sem contar que nesse percentual colocado, com o advento da Lei das Cotas, nós ainda temos uma questão muito séria que é a questão das fraudes na universidade, tem uma grande quantidade de denúncias, se estima que tenha 60 mil vagas ocupadas desde a Lei de Cotas (12.711/12) por não negros. Bem, e isso, de alguma forma reflete o racismo institucional que está posto, inclusive na universidade. Por quê? Porque se é necessário, por exemplo, ter todo um controle para a questão

\footnotetext{
5 Agradecemos pela contribuição da Pós-Doutoranda do NEAB (UEL) Mariana Panta, pelo seu conhecimento e generosidade na revisão do roteiro e sugestões pertinentes.
} 
das cotas por renda, de um e meio salário-minimo, e que é altamente controlado, por que a auto declaração ter um caráter exclusivo para poder acessar a politica de cotas?

Neste momento de pandemia, e em todos os momentos a população negra no ensino superior ou então na educação básica, tem uma série de desvantagens e não são apenas desvantagens estruturais, há uma série de desvantagens curriculares, metodológicas, tem um ambiente que nunca foi pensado para a questão da diversidade e para a maneira como as pessoas constroem a sua forma de estar no mundo assim como, também constroem a sua forma de aquisição do conhecimento. Temos políticas, nós temos dados estatísticos da maneira como, principalmente em tempos de pandemia, essas desigualdades se agravam, primeiro pelo acesso à internet, segundo pela questão do ambiente necessário para poder realizar essas práticas e, terceiro pela inadequação desse sistema de trabalho remoto que é muito diferente de um trabalho de uma educação à distância. São vários elementos que precisam ser considerados. Esse trabalho remoto não é uma educação à distância, e acima de tudo, não tem uma preparação para que esse se estabeleça observando a diversidade de estudantes que nós temos, e, principalmente, a diversidade dos estudantes cotistas. Se já é muito difícil presencialmente se adequar a esse espaço histórico e hegemonicamente branco e que entende apenas uma maneira de construção de conhecimento, imagine em tempos de pandemia.

Eu não sei quais seriam as alternativas, mas as alternativas de fazer um trabalho remoto, que dê conta de calendários, que forneça uma justificativa social, de alguma forma, exacerba sim, o aspecto da exclusão de negros e não negros neste ambiente acadêmico. O que que tem sido esse trabalho remoto? Quais são as perspectivas que se tem de construção desse trabalho remoto em lares onde a questão do acesso à internet, da construção do ambiente e, acima de tudo, um entorno que sempre foi extremamente desfavorável, em termos de resultados para isso?

Enfim, esse momento de pandemia exacerba as desigualdades porque essas políticas, mesmo as politicas de assistência de internet não dão conta da complexidade dos lares dessas pessoas, na verdade a pandemia atingirá os estudantes, mas também atingiu e muito as famílias desses estudantes, 
que certamente dentro da divisão social e da divisão racial do trabalho estão subempregados ou estão desempregados - e vivendo deste auxílio, cada vez mais diminuto. Neste momento parece que a pandemia se flexibilizou, que as pessoas estão morrendo menos, e se sabe que virá um outro ciclo. Enfim, eu penso que este é um momento extremamente dificil, as comunidades quilombolas - os remanescentes de quilombo que tem um processo específico de ingresso na universidade - não tem sinal de internet.

Temos que pensar, talvez este momento de pandemia devesse ser um momento de reflexão para quais rumos essa universidade teria que tomar, e sobre quais foram os mecanismos e os vícios que há muito tempo vem acontecendo, de modo que essa universidade continue sendo para poucos. Mesmo em tempos não pandêmicos, para a população negra que entra na universidade tem um vasto distanciamento, é um ambiente extremamente de estranhamento e não é apenas estrutural, no sentido de que é muito dificil manter essa universidade para as famílias que nunca estiveram nesse espaço, é um estranhamento epistêmico, pedagógico, no sentido de dizer que essas pessoas trazem outros tipos de conhecimento, outras formas de aprender, que não dialogam com a maneira como nós temos feito ciência, como nós temos reproduzido o conhecimento. É uma outra forma também corporal, é uma outra forma espiritual, é uma outra forma relacional com esse espaço construído em todas as suas instâncias a partir de um habitus hegemonicamente branco, ou seja, unicamente ocidental, hegemonicamente moderno dentro dessa modernidade que vem se reproduzindo, e que a gente esquece a sua gênese. Pensar o conhecimento moderno significa dizer, acima de tudo, que a gente esquece da morte do conhecimento que foi gestado, ou então das tentativas de morte de conhecimento que foram gestadas para que essa forma de aprender, para que esses conteúdos, para que esse fundamento do que é o conhecimento se funde como único e como verdadeiro.

Ana Paula e Eduardo: Pensando no caso do Brasil e do racismo como elemento estrutural em nossas sociedades, como a professora vê o reflexo da pandemia para a população negra, se comparado com os países centrais do capitalismo global? 
Georgina: A globalização como parte desse "projeto" de capitalismo global, hegemônico, produz o Sul Global e o Norte Global, nesse sentido, o teletrabalho é diferente na relação do contexto geopolítico onde venha a se efetivar. Todavia, não se discute sobre as particularidades, mas a concepção de mundo do trabalho que se estenderá quando o pós-pandemia se estabelecer. E, sim, as clivagens sociais aumentam com a pandemia do coronavírus, mas a pensar: quais serão as respostas? As respostas podem ser múltiplas, e, dentro dessa diversidade, muitas se repetem: a reprodução das respostas historicamente dadas às diversas crises, sejam elas sanitárias, civilizatórias ou mesmo a crise do capital (estas não são independentes), este último, pela forma como conquista domínios, principalmente estatais, tem saído de tais crises com fissuras. O teletrabalho tenderá a ser uma constante, talvez em sua forma híbrida, dentro da análise do que será benéfico/lucrativo para os anseios do capitalismo global, com todas as suas nuances. Em relação ao Brasil, as dificuldades tendem a ser agravadas, porque, contraditoriamente, graças ao mito da democracia racial e, consequentemente, ao racismo velado, vive-se em um país cujo racismo é o “crime perfeito", expressão utilizada pelo Prof. Kabenguele Munanga, que analisa a não assunção do racismo pelas pessoas e nem pelas instituições. Por isso, a inacreditável realidade de racismo sem a existência de racistas. $\mathrm{Na}$ atual conjuntura de um Estado brasileiro em que o ex-ministro da educação, em uma reunião governamental (realizada em 22/04/2020 e, posteriormente, divulgada nos meios de comunicação), reafirma que só existe um povo, que é o povo brasileiro, independentemente de etnia/raça, nada se pode esperar de políticas compensatórias que considerem que os óbitos e a pauperização tem raça/cor. Mas é necessário lembrar que a população negra sobreviveu a projetos de eugenia estatais e, certamente, encontrará mecanismos para dar continuidade às suas lutas, não apenas pela sobrevivência, mas na proposição de um projeto de sociedade.

Por fim, durante a pandemia as favelas, os quilombos, as reservas indígenas se "defenderam" contra o virus biológico e a virulência do Estado "necropolitico" (Achile Mbembe); as perdas foram inevitáveis, no entanto acredito que a luta contra o capitalismo global será correlata à luta contra o 
racismo, o machismo, a homofobia, que são também globais e interligadas, de modo que possam, muito além de denunciar, erradicar a simultaneidade de opressões (interseccionais) em determinados corpos. Esperemos, não sem esperança, por dias muito melhores.

\section{Sobre a entrevistada:}

Georgina Helena Lima Nunes possui graduação em Educação Física e Técnico em Desporto pela Universidade Federal de Pelotas, Especialização em Educação Psicomotora (URCAMP), Especialização em Educação UFPel, Mestrado em Educação pela Universidade Federal de Pelotas, Doutorado em Educação pela Universidade Federal do Rio Grande do Sul, Estágio PósDoutoral em Educação na Universidade do Oeste do Paraná (UNIOESTE). Atualmente é professora Associada da Universidade Federal de Pelotas, Faculdade de Educação, tem experiência na área de Educação, com ênfase em Educação Rural, Educação das Relações Raciais, Educação Quilombola e Gênero, Políticas Afirmativas no Ensino Superior. Líder do Grupo de Pesquisa Movimentos Sociais e Educação (MovSE), coordenadora do Observatório Interinstitucional em Ações Afirmativas. 